\section{From bedside to bench}

\section{By Kai-Jye Lou, Staff Writer}

The recently announced oncology R\&D collaboration between Sanofi and Massachusetts General Hospital takes a different tack than most translational research partnerships, as the two parties are starting with insights gleaned from the bedside setting and are working their way back to the bench. The partners have formed teams to take on joint projects that will help formulate and test new hypotheses on how to best position the pharma's cancer therapeutics and design the associated clinical programs.

Under the deal, Sanofi and three labs at the Massachusetts General Hospital Cancer Center will work together for at least two years on joint projects. The partners will share scientific expertise, R\&D capabilities and resources. Financial details are undisclosed.

"We've set up joint teams cochaired by lead scientists from Sanofi and MGH that will work together on projects to define what the translational roadmap should be for Sanofi's early stage candidates," said Donald Bergstrom, head of global translational and experimental medicine at Sanofi.

The pharma initially is bringing two molecules that have come out of its discovery labs along with some preliminary data suggesting the molecules could have utility for treating advanced tumors, including those that are intrinsically resistant or refractory to current drugs. The molecules go after new, undisclosed targets.

Bergstrom said the two compounds have key unaddressed translational questions, such as the ideal patient population to target and whether the therapeutics will be able to show clear evidence of benefit in the targeted population.

To address these questions and others, Sanofi needed preclinical models that faithfully recapitulated clinical scenarios in which the compounds could be applied. Bergstrom said this is where MGH comes in.

"What MGH scientists bring to this collaboration are their clinical insights and their expertise in translating such insights into preclinical models," Bergstrom told SciBX. "We chose to collaborate with MGH because we saw that the scientists were not only taking their work from bench to bedside but also taking information from the bedside back to the bench by developing preclinical models to recapitulate the issues they see in the clinic."

Such models, he said, include those that recapitulate drug resistance and refractory tumors seen in patients.

\section{Insights and opportunities}

Bergstrom noted that the first goal of the R\&D collaboration is to obtain better insights on how to position and develop Sanofi's early stage candidates. The other goal, he said, is to have the collaboration itself serve as a foundation for future translational partnerships with other parties.

In terms of milestones, the pharma wants to have data by next year that will either support or refute the case for developing an early stage candidate in a particular clinical setting.

Bergstrom said the preclinical translational models being developed at MGH will be used to both define and test hypotheses on how to develop a candidate.

"The teams will meet every two weeks to review project data and, if needed, modify current $R \& D$ roadmaps to better fit the new data," he added. "We will also constantly look at the project data for information on whether to continue developing a compound under an existing hypothesis or to develop it under a new hypothesis."

Bergstrom said the key criteria that will determine whether the collaboration gets extended are if Sanofi sees the collaboration as productive and whether the collaboration generates additional questions and hypotheses that need to be followed up on.

"I do think that there will be hypotheses that emerge from the projects that lead to extensions of existing research projections as well as to new research directions," he told SciBX.

Bergstrom said both Sanofi and MGH are incented to generate new IP under the collaboration. He declined to provide details.

Lou, K.-J. SciBX 5(43); doi:10.1038/scibx.2012.1129

Published online Nov. 1, 2012

\section{COMPANIES AND INSTITUTIONS MENTIONED}

Massachusetts General Hospital, Boston, Mass.

Massachusetts General Hospital Cancer Center, Boston, Mass.

Sanofi (Euronext:SAN; NYSE:SNY), Paris, France 